\title{
Potential Benefits and Obstacles of Implementing Driverless Train Operation on the Tyne and Wear Metro: A Simulation Exercise
}

\author{
Jonathan Peter Powell $^{1}$ - Anna Fraszczyk ${ }^{1} \cdot$ Chun Nok Cheong ${ }^{1} \cdot$ Ho Ki Yeung ${ }^{1}$
}

Received: 27 June 2016/Revised: 15 November 2016/Accepted: 20 November 2016/Published online: 2 December 2016

(C) The Author(s) 2016. This article is published with open access at Springerlink.com

\begin{abstract}
Metro systems around the world have many differences in their design and operation, one aspect of which is the level of automation. The most advanced technology available allows for unattended train operation with no staff on-board, which can bring a number of benefits. As a result, this is becoming increasingly common for new-build metro systems (such as the Dubai Metro), as well as for upgrades of traditional driver-led systems (such as Paris Métro Line 1). This paper uses the Tyne and Wear Metro as a case study to highlight the potential benefits and obstacles of implementing driverless trains on an existing metro system. This investigation has two parts: a review of the challenges of implementing increasing levels of automation for the existing Metro infrastructure and a simulation exercise to compare automatic train operation with manual driving on the core section of the Metro network. The results of the simulation exercise show that significant increases in the capacity of the Tyne and Wear Metro system are possible when automatic train operation is implemented in conjunction with resignalling. However, low adhesion conditions represent a significant risk to achieving this capacity increase reliably, and additional measures to mitigate low adhesion conditions would be required. The study also discusses the infrastructure upgrades required to convert an existing system to unattended train operation. The most significant obstacle for the Metro is that it mostly runs at ground level, with some
\end{abstract}

Jonathan Peter Powell

j.powel12@newcastle.ac.uk

1 NewRail - Centre for Railway Research, Newcastle University, Stephenson Building, Claremont Road, Newcastle upon Tyne NE1 7RU, UK

Editor: Xuesong Zhou sections shared with main line services. The costs associated with securing the tracks and ensuring compatibility with main line trains mean that the Metro is not a particularly promising application for driverless train operation at this time. Nonetheless, the issues discussed in the paper are very much relevant for other metro systems, and the methodology of this study is easily transferrable.

Keywords Metro · Automation - Driverless train . Simulation

\section{Introduction}

\subsection{Driverless Train Operation in Metro Systems}

Driverless vehicles are not a new technology for urban railway systems. The Post Office Railway, opened in 1927, was a fully automated underground narrow-gauge railway network that carried letters and parcels within central London, and required no staff on-board the trains [1]. The opening of the London Underground Victoria Line in 1968 marked the first complete passenger-carrying line with automatically driven trains, although a driver was present to supervise operations and operate the train doors. This followed a number of in-service trials of automatic train operation during the early 1960s, on metro systems in cities such as London [2, 3], New York [4, 5], Paris [6], Moscow [7], Stockholm [8] and Barcelona [9]. Automatic train operation also appeared on single purpose main lines during this decade, for example, the trials of automatic train operation (albeit drivers were retained) on the high-speed Tōkaidō Shinkansen in Japan [10], and the construction of the completely driverless Carol Lake iron ore railway in northeast Canada [4]. 
The Kobe Port Island Line (opened in 1981) can be considered to be the first passenger-carrying metro with no staff on-board the trains, defined as unattended train operation (UTO). This line uses rubber-tyred rolling stock. The steel-wheeled Vancouver SkyTrain followed in 1985, although the first two lines in the network use linear induction motors for propulsion. Copenhagen Metro opened in 2002 with UTO and conventional rolling stockdefined here as vehicles with steel wheels, running on steel rails for support, guidance and traction/braking.

Around a quarter of existing metro systems around the world now have UTO on at least one of their lines [11]. Table 1 summarises these lines, as recorded by the International Association of Public Transport (UITP) in their Atlas of Automated Metros [12].

Although a majority of the metro lines in Table 1 were designed and built as UTO systems from opening, the conversion of existing lines to driverless operation has been carried out in recent years, such as the Nuremberg U-Bahn Line 2 in 2010 and Paris Métro Line 1 in 2011. Further conversions of existing lines are currently either planned or underway. The specific aim of this paper is therefore to undertake a high-level examination of the potential benefits and obstacles of converting an existing metro system to driverless operation, using the Tyne and Wear Metro system as a case study.

\subsection{Organisation of the Paper}

The outline methodology of this study is twofold: firstly, an infrastructure assessment was carried out to investigate likely changes needed to the current system in order to be able to start running driverless trains on the Metro network. This assessment examines the current Metro infrastructure and rolling stock, in order to suggest the required improvements in line with automation standards and good practice from other driverless systems. Secondly, a simulation exercise was employed in order to examine the effect of automatic train operation on train movements within the network.

The contribution of this paper to the debate on automation of railways is to highlight the potential benefits and obstacles of implementing driverless trains identified by previous research, and then to describe in detail a simulation exercise to examine the capacity benefits of automation for an existing metro system.

Section 2 of the paper provides some background information, including the definition of grades of automation in Sect. 2.1.2 and a description of the chosen case study (the Tyne and Wear Metro) in Sect. 2.2. The methodology outlined above considers the challenge of introducing driverless operation from two perspectives: a qualitative assessment of infrastructure upgrade requirements and a simulation exercise to investigate the effects of automated operation. The main body of the paper presents and discusses the results of these investigations, with Sect. 3 concentrating on changes needed to existing infrastructure and Sect. 4 focusing on the simulations carried out. Section 5 includes some conclusions and recommendations for the future.

\section{Background Information}

\subsection{Definitions}

\subsubsection{Metro Systems}

There are a number of names used to describe different urban transport systems across the world, and these are not necessarily used consistently. The focus of this paper is on metro systems, as defined by UITP [13]:

Metropolitan railways are urban, electric transport systems with high capacity and a high frequency of service. Metros are totally independent from other traffic, road or pedestrians. They are consequently designed for operations in tunnel, viaducts or on surface level but with physical separation.

This definition typically not only refers to conventional railway systems with steel wheels running on steel rails, but also includes rubber-tyred, monorail and magnetically levitated systems. Table 1 shows that these unconventional systems make up a significant share of the total number of driverless metros.

\subsubsection{Grades of Automation}

It can also be seen from the Introduction that there are a number of different functions on a train that can be automated, with different roles for staff in each case. UITP provides a standard definition of Grades of Automation (GoA) to reflect this [11], as encompassed in the IEC 62267 standard. This is summarised in Table 2, based on four criteria: setting a train in motion, stopping a train, door closure and operation in event of disruption.

All functions of a vehicle are controlled by a driver for Grade 0 (GoA 0), reflecting historic railway practice but no longer typical for metro systems. Grades 1 (GoA 1) and 2 (GoA 2) both require a driver on-board, but include some degree of automatic train protection (ATP). ATP is installed to prevent collisions, and will automatically apply the brakes if the train passes a red signal or is travelling too fast. GoA 2 also includes automatic train operation (ATO) to control the movement of the train during regular operation. Grades 3 (GoA 3) and 4 (GoA 4) of automation 
Table 1 UTO lines across the world

\begin{tabular}{|c|c|c|c|c|c|}
\hline City & Line & Year opened & Length (km) & Stations & Technology \\
\hline Kobe & Port Island Line & 1981 & 11 & 12 & Rubber tyre \\
\hline Osaka & Nankō Port Town Line & 1981 & 8 & 10 & Rubber tyre \\
\hline Lille & Lille Metro Line 1 & 1983 & 13 & 18 & Rubber tyre \\
\hline Vancouver & Expo Line & 1985 & 29 & 20 & Linear motor (LIM) \\
\hline Miami & Metromover & 1986 & 7 & 21 & Rubber tyre \\
\hline Detroit & Detroit People Mover & 1987 & 5 & 13 & Linear motor (LIM) \\
\hline Lille & Lille Metro Line 2 & 1989 & 32 & 44 & Rubber tyre \\
\hline Yokohama & Kanazawa Seaside Line & 1989 & 11 & 14 & Rubber tyre \\
\hline Kobe & Rokkō Island Line & 1990 & 5 & 6 & Rubber tyre \\
\hline Lyon & Lyon Metro Line D & 1991 & 13 & 15 & Rubber tyre \\
\hline Paris & Orlyval & 1991 & 7 & 3 & Rubber tyre \\
\hline Toulouse & Toulouse Metro Line A & 1993 & 13 & 18 & Rubber tyre \\
\hline Tokyo & New Transit Yurikamome & 1995 & 15 & 16 & Rubber tyre \\
\hline Taipei & Taipei Metro Line 1 (Wenhu Line) & 1996 & 25 & 24 & Rubber tyre \\
\hline Kuala Lumpur & Kelana Jaya Line & 1998 & 29 & 24 & Linear motor (LIM) \\
\hline Paris & Paris Métro Line 14 & 1998 & 9 & 9 & Rubber tyre \\
\hline Singapore & Bukit Panjang LRT Line & 1999 & 8 & 14 & Rubber tyre \\
\hline Vancouver & Millenium Line & 2002 & 20 & 13 & Linear motor (LIM) \\
\hline Rennes & Rennes Metro Line A & 2002 & 9 & 15 & Rubber tyre \\
\hline Copenhagen & Copenhagen Metro line M1 and M2 & 2002 & 21 & 22 & Conventional rail \\
\hline Singapore & Sengkang LRT Line & 2003 & 11 & 14 & Rubber tyre \\
\hline Singapore & North East MRT Line & 2003 & 20 & 16 & Conventional rail \\
\hline New York & AirTrain JFK & 2003 & 13 & 10 & Linear motor (LIM) \\
\hline Las Vegas & Las Vegas Monorail & 2004 & 7 & 8 & Monorail \\
\hline Nagoya (Aichi) & Linimo & 2005 & 9 & 9 & Magnetic levitation \\
\hline Hong Kong & Disneyland Resort Line & 2005 & 4 & 2 & Conventional rail \\
\hline Turin & Turin Metro Line 1 & 2006 & 13 & 21 & Rubber tyre \\
\hline Toulouse & Toulouse Metro Line B & 2007 & 15 & 20 & Rubber tyre \\
\hline Tokyo & Nippori-Toneri Liner & 2008 & 10 & 13 & Rubber tyre \\
\hline Lausanne & Lausanne Métro line M2 & 2008 & 6 & 14 & Rubber tyre \\
\hline Nuremberg & Nuremberg U-Bahn line U3 & 2008 & 7 & 9 & Conventional rail \\
\hline Dubai & Palm Jumeirah Monorail & 2009 & 6 & 4 & Monorail \\
\hline Singapore & Circle MRT Line & 2009 & 36 & 30 & Conventional rail \\
\hline Vancouver & Canada Line & 2009 & 19 & 16 & Conventional rail \\
\hline Dubai & Dubai Metro Red Line & 2009 & 52 & 27 & Conventional rail \\
\hline Barcelona & Barcelona Metro Line 9 and Line 10 & 2009 & 10 & 12 & Conventional rail \\
\hline Nuremberg & Nuremberg U-Bahn line U2 & 1984 & 14 & 16 & Conventional rail \\
\hline São Paulo & São Paulo Metro Line 4 (Yellow) & 2010 & 10 & 6 & Conventional rail \\
\hline Guangzhou & Zhujiang New Town APM & 2010 & 4 & 9 & Rubber tyre \\
\hline Busan & Busan Subway Line 4 & 2011 & 13 & 14 & Rubber tyre \\
\hline Busan & Busan-Gimhae Light Rail Transit & 2011 & 24 & 21 & Conventional rail \\
\hline Dubai & Dubai Metro Green Line & 2011 & 23 & 18 & Conventional rail \\
\hline Seoul & Shinbundang Line & 2011 & 31 & 12 & Conventional rail \\
\hline Paris & Paris Métro Line 1 & 1900 & 17 & 25 & Rubber tyre \\
\hline Uijeongbu & U Line & 2012 & 11 & 15 & Rubber tyre \\
\hline Milan & Milan Metro Line 5 & 2013 & 13 & 19 & Conventional rail \\
\hline Brescia & Brescia Metro & 2013 & 14 & 17 & Conventional rail \\
\hline Yongin & Everline & 2013 & 18 & 15 & Linear motor (LIM) \\
\hline
\end{tabular}


Table 1 continued

\begin{tabular}{llllll}
\hline City & Line & Year opened & Length $(\mathrm{km})$ & Stations & Technology \\
\hline Singapore & Downtown MRT Line & 2013 & 21 & 18 & Conventional rail \\
Budapest & Budapest Metro Line 4 & 2014 & 7 & 10 & Conventional rail \\
Rome & Rome Metro Line C & 2014 & 18 & 21 & Conventional rail \\
Daegu & Daegu Metro Line 3 & 2015 & 24 & 30 & Monorail \\
Incheon & Incheon Subway Line 2 & 2016 & 29 & 27 & Conventional rail \\
\hline
\end{tabular}

Table 2 Grades of train automation

\begin{tabular}{|c|c|c|c|c|c|c|}
\hline $\begin{array}{l}\text { Grade of } \\
\text { Automation } \\
(\mathrm{GoA})\end{array}$ & $\begin{array}{l}\text { Type of train } \\
\text { operation }\end{array}$ & $\begin{array}{l}\text { Setting train } \\
\text { in motion }\end{array}$ & $\begin{array}{l}\text { Stopping } \\
\text { train }\end{array}$ & Door closure & $\begin{array}{l}\text { Operation in } \\
\text { event of } \\
\text { disruption }\end{array}$ & Example \\
\hline GoA 0 & Driver without ATP & Driver & Driver & Driver & Driver & On-street trams \\
\hline GoA 1 & Driver with ATP & Driver & Driver & Driver & Driver & Tyne and Wear Metro \\
\hline GoA 2 & $\begin{array}{l}\text { ATP and ATO } \\
\text { with driver }\end{array}$ & Automatic & Automatic & Driver & Driver & Paris Métro Line 3 \\
\hline GoA 3 & DTO & Automatic & Automatic & Train attendant & Train attendant & Docklands Light Railway \\
\hline GoA 4 & UTO & Automatic & Automatic & Automatic & Automatic & Dubai Metro \\
\hline
\end{tabular}

$A T P$ automatic train protection, ATO automatic train operation, DTO driverless train operation, UTO unattended train operation

correspond to driverless or unattended train operation, without an on-board driver's involvement (ATP and ATO functions are still a part of the system). GoA 3 retains an attendant on-board to operate doors, assist passengers and operate the train in case of equipment failures. In GoA 4, a train is fully automatic, as all the four criteria listed in Table 2 can be executed without a physical presence of a human on board. The trains are effectively monitored and controlled by staff based in a remote control centre.

In this paper, the stated aim of examining 'driverless operation' on the Tyne and Wear Metro covers both GoA 3 and GoA 4. Some of the benefits associated with automating train operation would also materialise under GoA 2, and so these are also referred to in the investigation.

\subsection{Case Study: The Tyne and Wear Metro}

The Tyne and Wear Metro system is centred on Newcastle upon Tyne in the northeast of England. It was opened progressively from 1980, with some sections converted from former main line routes and some new alignments [14-16]. The network was subsequently extended to Newcastle International Airport in 1991 and to South Hylton in 2002 [17]. The latter extension runs over tracks owned by Network Rail (the national railway infrastructure manager), whereas the Metro infrastructure is owned and managed by Nexus (a local public body). On this section, Metro and main line services share the same tracks between Pelaw and Sunderland. Annual passenger numbers for the network are currently around 40 million per year, which is relatively modest for a network of this size. The system has 60 stations, served by two lines: the $51 \mathrm{~km}$ Yellow line between St James and South Shields, and the $36 \mathrm{~km}$ Green line between the Airport and South Hylton (both lines share the same tracks in the $10 \mathrm{~km}$ corridor between South Gosforth and Pelaw). The network is illustrated in Fig. 1.

The Metro is currently operated with the original rolling stock and signalling. The Metrocars are manually driven, with 2- and 3-aspect lineside colour light signalling, and are fitted with Indusi intermittent automatic train protection (ATP) system. The shared section between Pelaw and Sunderland has standard British 4-aspect colour light signalling, although Indusi has been fitted to all signals for the Metrocars, as well as AWS and TPWS at every signal for main line trains.

The Metro is currently undergoing an extensive renewal and modernisation programme, and the current strategy [18] intends to replace the Metrocars by 2025. The signalling and communication systems also require extensive renewal or replacement around this time. One of the options under consideration to improve the service offered by the Metro is driverless operation. This has the potential to support more frequent services in the busy central core between South Gosforth and Pelaw, which may be required if passenger numbers increase from their current levels, or if new lines are added to the system. Driverless operation 


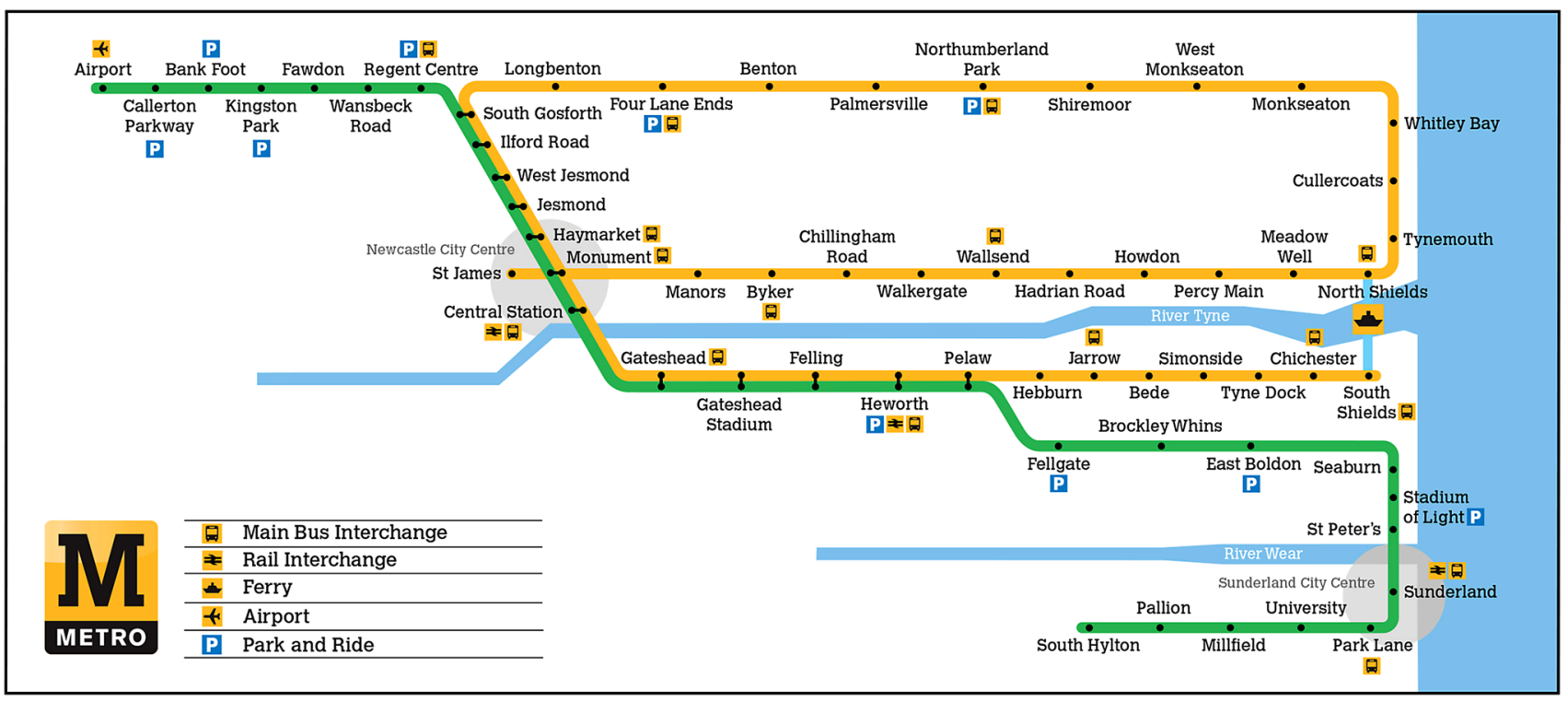

Fig. 1 Tyne and Wear Metro map (CNexus)

can also change the role of the driving staff to improve the service offered. The strategy documents suggest there are two key areas in which further investigation would be useful: more detailed research into the advantages and disadvantages of the fundamental operational changes that driverless operation could achieve, and the potential capacity constraints in the central core of the system. These areas are broadly aligned with the aims of this paper and are considered in the following sections.

\section{Qualitative Infrastructure Assessment}

\subsection{Overview}

A decision to implement driverless operation on a new or existing metro system requires the costs and benefits to be systematically assessed. An early discussion of the justifications for automating railways took place at an Institution of Mechanical Engineers Convention in London in September 1964, and this paper references a number of the studies presented there. A literature review of the benefits of automation was carried out a few years later by Milroy [19], and the key benefits may be summarised as increasing the service quality through greater capacity/traffic frequency, timetable flexibility and punctuality of trains. Train speed profiles may also be optimised to reduce energy consumption. In addition, staff costs can be significantly reduced, or staff (including ex-drivers) can be redeployed to assist passengers directly. These findings have been echoed in the more recent literature, both in general studies of automation [5, 20-25] and case studies of specific lines [26-29]. The continued growth in automated metro systems across the world suggests there are many cities for which these benefits are considered sufficient for adoption of the technology.

However, there are obstacles to adoption, with the severity of these depending on the individual characteristics of the metro system in question. The costs of the control and safety systems are higher when human drivers are no longer present, and can prevent the viability of a given project. In addition, the opposition of some passengers and staff to automation can also be a formidable obstacle [30, 31]. The following sub-sections consider these benefits and obstacles in more detail in the context of the Tyne and Wear Metro case study.

\subsection{Benefits of Automation}

\subsubsection{Automatic Train Operation (GoA 2)}

Automatic train operation (GoA 2) brings a number of benefits, which also apply to driverless trains at GoA 3 and 4. There is a large amount of literature on this topic, and so this sub-section provides a brief summary. The benefits associated with ATO stem from consistent control of train speed profiles [4, 19, 24, 32, 33] and greater potential for traffic management strategies to be implemented directly $[5,21,22]$. These benefits include an increase in the frequency of trains, and/or better recovery from delaysessentially an increase in the capacity of the system. The automation of routine but high-stress driving tasks increases the safety of the system by reducing the potential for human error $[4,19,25]$. Individual train speed profiles can 
also be controlled precisely to minimise energy consumption for a given journey time, including real-time optimisation to take delays into account [2, 34, 35]. Finally, smoother changes of acceleration compared to manual control may increase the lifespan of wheelsets and traction/ braking equipment [19], and can also improve passenger comfort $[22,36]$.

Instead of using ATO to increase the number of trains, it is also possible to take advantage of the more precise control of ATO to reduce the total fleet size [5], reduce the maximum rating of the electrical power supply system or major civil engineering structures [26]. As the Tyne and Wear Metro is an established system, this is less relevant than the benefits outlined in the first paragraph however.

\subsubsection{Staff Roles at GoA 3}

At GoA 3, the role of drivers is changed to an on-board passenger-facing role to assist passengers (improving the service quality), and carry out revenue protection (reducing costs of this task if it is currently performed by separate staff). Furthermore, their presence can help improve actual and perceived personal security [21,23]. Personal security risks are one of the main issues of concern for Metro passengers, and this issue can discourage off-peak travel in particular [18]. A separate permanent staff presence for security is considered unaffordable, and is currently limited to revenue protection officers that check a small proportion of train services, and an occasional police presence. Driverless operation provides an opportunity to provide a greater on-train presence without increasing staff costs.

In addition, the former driver's cab can be converted to additional passenger accommodation. The Metro runs short trains, typically a pair of $28 \mathrm{~m}$ Metrocars, and so the removal of cab areas can free up a considerable amount of passenger space relative to the train length. The cabs are only half width, but six extra seats per Metrocar could be added, assuming no extra standing room is created. For comparison, the current layout has 62 seats per Metrocar; the total crush loaded capacity of each Metrocar is around 300 people.

\subsubsection{New System Operations Concepts at GoA 4}

One of the most important changes for GoA 4 is that trains no longer need to be staffed at all, which can significantly reduce staff costs and increase the flexibility of the timetable, as the marginal cost of running additional trains is much reduced [19, 23, 24]. Many GoA 4 systems do have staff on trains and stations, but the key difference to GoA 3 is that the system is capable of operating without any members of staff present if necessary. This eases staff recruitment and rostering constraints [33], as well as making the system more resilient to industrial action by trade unions.

The removal of rostering constraints and the low marginal costs of running extra trains allow a change in the concept of operation: a greater number of (short) trains providing much more frequent services to a variety of destinations. GoA 4 also provides much greater flexibility, allowing train frequencies to be better matched to demand at peak and off-peak times. This offers a much better service to potential passengers, with high frequencies in particular likely to drive an increase in passenger numbers $[5,23-25,33]$. While unlikely to make much difference in heavily used metro lines that run long trains at high frequencies throughout the day, this is ideally suited for a more lightly used network with several interconnected lines such as the Metro. Many of the systems highlighted in Table 1 are operated on these principles, with GoA 4 the key feature that allows a high frequency service to be commercially viable for relatively modest passenger numbers.

\subsection{Obstacles to Implementation}

\subsubsection{Infrastructure}

The first major cost of ATP (GoA 1) and ATO (GoA 2) is modification or replacement of the rolling stock and signalling system, and the additional complexity may increase costs compared to other signalling and control systems [23]. Signalling costs for different metro systems do depend on the characteristics of the system in question however, in particular the amount of lineside equipment required by different signalling systems. It is likely to be more cost effective to design and fit ATP and ATO when a line is built, or undergoes resignalling and/or rolling stock replacement, but it is certainly possible to retrofit at a later date. Closure of an existing system for an extended period of time for conversion is likely to be difficult and expensive, as established metro lines are often vital links in a city's transport network [37]. It has already been noted in Sect. 2.2 that both the rolling stock and signalling of the Metro are due for replacement in the mid-2020s as they are near (or already past) the end of their economic life. However, one significant constraint is the section where Metro trains run over Network Rail infrastructure. This is unusual for a metro system, but means that any resignalling must remain compatible with main line trains using this route.

To ensure the high levels of safety associated with GoA 3 or 4 operation, the tracks are likely to require a greater degree of physical segregation from the surrounding environment than for trains where the driver is able to react to out of course or unexpected events such as trespassers, 
fallen trees or damage to infrastructure [23, 37]. Although not necessarily a significant issue for underground lines, this becomes most important when converting surface infrastructure that was not originally designed for such a high degree of isolation. A very high proportion of the tracks on which driverless trains currently operate are either underground or elevated [12]. By contrast, most the Metro is at ground level, and it is likely that lineside fencing would have to be upgraded, as trespass is a daily problem on Metro tracks [18]. Large and intrusive fencing would be contentious where the lines run close to houses in residential areas, however, and additional security personnel to detect and respond to intrusions may also be required. There are several level crossings for roads and footpaths, and these would have to be replaced with bridges or to be closed. This is likely to be difficult and expensive, as the five level crossings are all close to road junctions and surrounded by buildings.

The edges of platforms must also be protected [5]. Around $85 \%$ of stations on automated lines are fitted with platform screen doors or gates, with $15 \%$ implementing intrusion detection systems based on infra-red scanners or similar technology [11]. Platform screen doors remove the risk of passengers on the track completely, but intrusion detection systems can only partly mitigate the risk, as it is still possible for passengers to fall (or jump, in case of suicides) directly in front of the train, or between coupled vehicles. Passenger misuse of doors is still a problem, and this is typically the most common cause of delays on UTO systems, while false alarms from intrusion detection systems are also a potential source of delay [5]. The Metro and main line services share a platform at Sunderland, and platform screen doors spaced to the Metro door locations would not be compatible with main line stock with a different door pattern, so an intrusion detection system would be required here.

Improved communication and monitoring systems for the passengers are required throughout the system, especially for GoA 4 operation, to provide functions that would otherwise be carried out by a member of staff [21, 22, 24]. This also applies to remote monitoring and correction (where possible) of faults in equipment by a remote control centre. The equipment requires high levels of reliability and availability to ensure passenger safety [21]. Such systems would represent additional capital and maintenance costs for the Metro.

\subsubsection{Public Attitudes and Staff Opposition}

Public attitudes towards driverless operation are currently mixed [31], with some passengers worried about the safety of trains controlled automatically and without direct human supervision. Removing potential human errors, together with the additional safety measures highlighted in Sect. 3.3.1 above, means that driverless metro systems can be safer than those under human control [25]. Public awareness of successfully established driverless metros, together with the more general trends of increased acceptance of technology, makes it likely that fewer and fewer passengers will be against travelling on driverless trains, if indeed they even notice at all $[5,21]$. Personal security is typically a more significant consideration for passengers than whether or not the train is controlled automatically [21, 23], and Sect. 3.2.2 considered the benefits of moving drivers to on-board customer service roles in this respect. It should also be noted that the majority of the Metro stations are not staffed, which may limit the number of totally unstaffed trains that are acceptable to passengers.

There has also been considerable opposition to increased automation by trade unions, typically due to the potential for job losses/staff relocations, although safety concerns are often cited as a reason [5, 30, 38]. Section 3.2.2 already highlighted that a benefit of automating train operations is to remove the routine but high-stress driving tasks, and it can therefore be presented as an opportunity to provide more varied and interesting roles for staff $[5,25,38]$. The Paris Métro has demonstrated that constructive engagement with unions is possible, and conversion of Line 1 was considered a success from an industrial relations point of view, with redeployment to other lines or roles and offers of early retirement meaning that no compulsory redundancies were required [38]. London Underground is looking to move towards driverless trains, but at present the RMT and Aslef unions in the UK remain very hostile [39], and it is highly likely that the Metro would face the same problem with these unions. However, Glasgow Subway has successfully negotiated with the UNITE union to start implementing UTO [40], which demonstrates that it is possible in the UK.

\subsection{Findings}

A decision to implement driverless operation on a new or existing metro system requires the costs and benefits to be systematically assessed. GoA 3 and GoA 4 operations require substantial capital investment in signalling and control technologies, additional communication and monitoring systems, as well as measures to restrict access to the tracks and deal with out of course events. These capital costs are set against improvements in the quality of service delivered, the amount of passenger growth that results, and potential reductions in operating costs. The final decision will very much depend on the specific characteristics of the system in question. While mixed operation of different GoA is possible to obtain some of the service quality 
benefits, it risks incurring both high capital costs and disproportionate increases in operational costs too.

The moderate passenger numbers, lower off-peak demand and variety of destinations on the Tyne and Wear Metro network suggest that operation at GoA 4 could bring significant improvements in the service offered to passengers, by running a higher number of (shorter) trains to a variety of destinations. However, the Metro has some specific features that make driverless operation more difficult to implement by comparison with other metro systems. The majority of the tracks are at ground level, and measures to physically separate the tracks are likely to be both expensive and difficult to gain approval for. A significant part of the Green line is shared with main line services on Network Rail infrastructure, which means signalling and platform edge protection must remain compatible with other trains, and gaining acceptance for driverless operation over Network Rail infrastructure is an additional difficulty.

There are a number of future trends that may tip the balance towards adoption however. There is currently a significant amount of research and development work being carried out for driverless vehicles in the automotive sector. Roads are by nature more accessible to outside influences than railway tracks, and so much of this work is focused on improving hazard detection systems. Technology transfer may therefore have some potential to accelerate development and reduce the costs of these systems for driverless trains, in turn helping adoption of driverless operation on lines that are not fully elevated/underground. Main line railways that are close to their capacity limits are following metro system trends in signalling and control systems, for example, the recent development work of ATO over the European standard ETCS signalling system [41, 42]. This may bring about greater interoperability of ATO systems and ease the potential signalling compatibility issues when automated metro services run over main line infrastructure. Therefore, it is worth considering the increased capacity that automation can provide for the Metro, and this is the subject of Sect. 4.

\section{Simulation Exercise}

\subsection{Comparing Manual Driving and Driverless Operation}

Section 2.1.2 described the different Grades of Automation (GoA) defined by UITP, with manual driving of trains in GoA 0 and 1, and automatic train operation (ATO) in GoA 2, 3 and 4. The benefits of introducing ATO over manual driving are more consistent performance: closer working to line speeds and avoidance of 'over-cautious' station and signal approaches [32], which in turn can support greater network capacity. The aim of the simulations carried out for this study was therefore to compare the capacity of the Tyne and Wear Metro under manual driving (GoA 0 and 1) with ATO (GoA 2, 3 and 4-which therefore covers driverless trains).

The Tyne and Wear Metrocars have camshaft control of their electric traction equipment, and as such the maximum acceleration is always demanded. The ATP system on the Metrocars is intermittent, protecting against signal overruns but not providing continuous speed supervision. As such, manual driving can maintain the average cruising speed at close to the line speed limit. The key difference between manual driving and ATO for the Metrocars is therefore during braking, where ATO can provide a higher average deceleration than less consistent (and more cautious) manual driving [43].

The average in service deceleration achieved with manual driving during braking of the Metrocars has been measured at $0.5 \mathrm{~m} / \mathrm{s}^{2}$ by previous work, well below the full service braking figure of around $1.3 \mathrm{~m} / \mathrm{s}^{2}$ [43]. For ATO, the London Underground Central Line can be used as a point of comparison. This uses a target deceleration of $0.75 \mathrm{~m} / \mathrm{s}^{2}$ when running above ground and $1.15 \mathrm{~m} / \mathrm{s}^{2}$ in underground sections. The full service maximum here is also around $1.3 \mathrm{~m} / \mathrm{s}^{2}$, and this provides an illustration of the differences in deceleration levels for manual driving and ATO referred to above. However, when the Central line ATO system was first introduced, there were significant issues with low wheel/rail adhesion levels on above-ground sections, with wheel slide under braking resulting in unacceptable levels of wheel flats and station overruns. Low adhesion conditions on the line are most commonly reported during autumn, typically due a combination of light rain and fallen leaves on the rails. When these conditions are present, the ATO target deceleration is reduced to $0.55 \mathrm{~m} / \mathrm{s}^{2}$, in addition to other mitigation measures such as railhead treatment [44].

The use of ATO makes it more practical to implement moving block signalling [22, 32], and the two technologies are frequently implemented together on driverless metro systems around the world. Therefore, the replacement of the existing fixed block lineside signalling by a moving block signalling system was also considered for the simulation work described in this paper.

\subsection{Experimental Method}

This study builds on a previous experience with rail simulation work at Newcastle University. The Metro has previously been modelled using discrete event-based simulation software packages, such as Simul8 [45] and Arena [46]. For this study, continuous physics-based 
simulation software was required to predict the effects of changing deceleration levels on inter-station journey times and investigate the resulting changes to the interaction between trains, and hence determine the influence on capacity. OpenTrack multi-train simulation software (v1.7.5) was used for the modelling and simulation work. A model of the Metro system had been built and validated against measured speed profile and energy consumption data in a previous project. For this study, the capacity of the central corridor between South Gosforth and Pelaw was analysed. The boundaries of the study were therefore set to be Regent Centre, Longbenton, Hebburn and Fellgate, so that the constraints of the flat junction at South Gosforth and the single line section to Hebburn were included.

Landex [47] discussed a number of different ways to define capacity, and subsequently detailed the standard UIC 406 method of measuring it [48]. This method has been widely adopted for studies of capacity in metro systems [49]. The theoretical maximum capacity of a line is first calculated by compressing the timetable-i.e. reducing the headway (separation) between trains to the minimum possible. A timetable based on this maximum theoretical capacity would have no resilience against delays however, and as such would not be practical for day-to-day operations. Real timetables therefore include additional time margins that increase the headway between trains, which gives the practical capacity of the line for a given level of timetable stability.

The current (2016) Metro timetable has a maximum of 20 trains per hour (tph) through the central core at peak times, and this was implemented in the OpenTrack model as the baseline for practical capacity. The simulation was based on the assumption of an 'all-out' driving style to maximise capacity, with maximum acceleration, cruising at line speed and then braking, with no coasting. The current train lengths were assumed to remain the same. The maximum theoretical capacity was obtained by reducing the headway between trains in the model to the minimum possible before OpenTrack identified signalling conflicts starting to occur. Figure 2 illustrates this timetable compression process for trains running between Jesmond and Central Station under the existing fixed block signalling. In this example, reducing the headway any further would create a signalling conflict at Jesmond. The minimum headway for the overall timetable was used to evaluate the ratio between practical and theoretical capacity, which worked out as $76 \%$ for the current timetable.

The rolling stock deceleration specified in the OpenTrack model was then modified to examine the effects of ATO in accordance with Sect. 4.1, and the new maximum theoretical capacity obtained by the same compression method as before. This new maximum capacity value was then multiplied by the $76 \%$ ratio for capacity utilisation derived above, and rounded down to the nearest integer value to provide an estimate of practical capacity (in tph). The OpenTrack model was also modified to replace the existing lineside signalling with a moving block signalling system. This capacity estimation process was repeated for all of the combinations of manual driving/ATO and lineside/moving block signalling. Low adhesion conditions were also tested for the ATO case, with both lineside and moving block signalling, again by modifying the deceleration value in accordance with Sect. 4.1.

An additional benefit of ATO identified in Sect. 3.2.1 was better recovery from delays, some of which is derived from the parallel use of moving block signalling [32]. This means that it could be possible to reduce the additional time margin between trains, while still maintaining a given level of timetable stability. This would effectively increase the capacity utilisation above the $76 \%$ ratio derived for the current timetable with manually driven trains. A sensitivity test was therefore carried out using ratios of 80,85 and $90 \%$ for the various ATO cases to examine the possible increases in the number of trains in the timetable.

As well as changes to signalling and control, Nexus are also considering new rolling stock, with a higher maximum speed of $100 \mathrm{~km} / \mathrm{h}$ [18]. The current Metrocars have a maximum speed of $80 \mathrm{~km} / \mathrm{h}$, and the camshaft control results in a sawtooth profile for the tractive effort at low speeds, providing an average acceleration of around $1.15 \mathrm{~m} / \mathrm{s}^{2}$. The OpenTrack model was therefore modified to also test this case. The new rolling stock characteristics were based on the London Underground Central Line rolling stock, with a maximum speed of $100 \mathrm{~km} / \mathrm{h}$ and a constant initial acceleration of $1.3 \mathrm{~m} / \mathrm{s}^{2}$, although the maximum power rating of the traction equipment was assumed to be the same as the existing Metrocars. Where the current line speed is $80 \mathrm{~km} / \mathrm{h}$, it was assumed that this could be raised to $100 \mathrm{~km} / \mathrm{h}$ in the model. Much of the central core of the Metro is restricted to lower speeds however, typically due to line curvature, and these restrictions were left in place. All six combinations of manual/ATO/low adhesion ATO and lineside/moving block signalling were tested with the revised train performance and line speeds.

One of the assumptions in the timetable modelling was a nominal dwell time of $30 \mathrm{~s}$ at each station. The dwell time can potentially have a significant effect on the capacity of a metro system $[24,50]$. As such, a second sensitivity test was carried out for the capacity in the baseline case of manual driving and lineside signalling, using dwell times of $15,30,45$ and $60 \mathrm{~s}$.

There are three remaining assumptions in the modelling that are not yet detailed. The safety distance for the moving block signalling system was assumed to be $150 \mathrm{~m}$, identical to the safety overlaps in the existing fixed block 
Fig. 2 Extract from train graph, illustrating compression method for Jesmond to Central Station trains

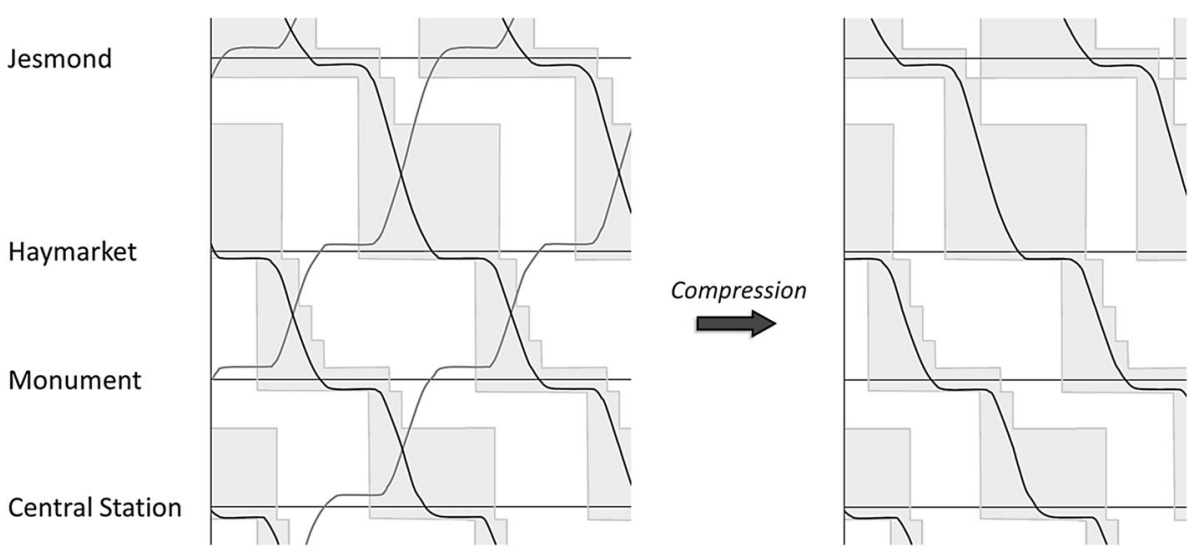

signalling. Train mass is assumed constant, based on a typical passenger load. The Metrocars have load weighing in traction and braking, so the effect on journey times (and hence capacity) of variation in mass is minimal. Finally, the power rating of the overhead line equipment and substations is assumed to be sufficient to support additional trains. The power supply system would require an additional investigation to determine the changes required with a revised timetable, but this is out of scope of this study, as the focus is on the potential capacity increases made possible by ATO.

\subsection{Results and Discussion}

\subsubsection{Capacity Results}

The results for practical capacity through the central core section of the Tyne and Wear Metro are given in Table 3, in terms of trains per hour (tph). The use of either ATO or moving block signalling in isolation allows an increase from the currently timetabled 20 to $22 \mathrm{tph}$, but implementing the two technologies together allows an increase to $30 \mathrm{tph}$. As such, both should be implemented together to obtain the maximum capacity benefits from these technologies.

The figure of $30 \mathrm{tph}$ is reasonable by comparison with what has been achieved on other urban rail systems across the world [24]. Although resignalling is one of the prerequisites to achieving these benefits, moving block is not an absolute requirement, as it is possible for in-cab fixed block signalling with shorter blocks to approach the capacity provided by moving block.

However, Table 3 also indicates that low adhesion conditions are sufficient to negate nearly all of the capacity benefits of ATO/moving block signalling, with the necessary mitigation measures identified in Sect. 4.1 reducing the capacity from 30 to 23 tph. On the London Underground Central Line, the core section is almost entirely underground, and the majority of the adhesion issues are encountered at the outer ends of the line where service density is typically lower. On the Tyne and Wear Metro, a significant proportion of the central core section is above ground, including a number of tree-lined cuttings, which are one of the most problematic areas for low rail adhesion. Measures to mitigate low adhesion may include vegetation management, fitting sanders to rolling stock, rail head treatment trains or more radical options such as linear motor technology [51, 52]. Conventional (adhesionworked) railways make up a minority of GoA 4 metro systems in Table 1, and it is only recently that they have become more common; the risk associated with low adhesion conditions are likely to be partly responsible for this trend.

\subsubsection{Increased Capacity Utilisation}

The results of the sensitivity study for increasing the capacity utilisation ratio are given in Table 4, for ATO with existing signalling and ATO with moving block, for both normal and low adhesion conditions. The size of the increase for increasing the capacity utilisation ratio is significant.

Further detailed investigation of a specific signalling/control system and timetable would be required to determine whether an increase in the capacity utilisation ratio would be possible while still retaining an acceptable level of timetable stability however.

\subsubsection{Higher Performance Rolling Stock}

The higher performance rolling stock had little effect on these results, typically only changing the headway by around 2-3 s. This is likely due to the close station spacing and number of speed restrictions in the central core of the Metro, which means that there is little opportunity to take advantage of an increased top speed. The advantages of this increase in top speed would be seen in journey times on the outer parts of the network, where there is greater 
Table 3 Simulation results

\begin{tabular}{llll}
\hline & $\begin{array}{l}\text { Manual driving }\left(0.5 \mathrm{~m} / \mathrm{s}^{2}\right. \\
\text { deceleration) }(\mathrm{tph})\end{array}$ & $\begin{array}{l}\text { ATO }\left(0.75 \mathrm{~m} / \mathrm{s}^{2} \text { deceleration }\right) \\
(\mathrm{tph})\end{array}$ & $\begin{array}{l}\text { ATO-low adhesion }\left(0.55 \mathrm{~m} / \mathrm{s}^{2}\right. \\
\text { deceleration })(\mathrm{tph})\end{array}$ \\
\hline Existing lineside signalling & 20 & 22 & 20 \\
Moving block signalling & 22 & 30 & 23 \\
\hline
\end{tabular}

Table 4 Sensitivity test for capacity utilisation ratio

\begin{tabular}{lllll}
\hline $\begin{array}{l}\text { Capacity } \\
\text { utilisation }(\%)\end{array}$ & $\begin{array}{l}\text { ATO } \\
\text { only (tph) }\end{array}$ & $\begin{array}{l}\text { ATO, low } \\
\text { adhesion (tph) }\end{array}$ & $\begin{array}{l}\text { ATO, moving } \\
\text { block (tph) }\end{array}$ & $\begin{array}{l}\text { ATO, moving block/ } \\
\text { low adhesion (tph) }\end{array}$ \\
\hline 76 (as above) & 22 & 20 & 30 & 23 \\
80 & 23 & 21 & 32 & 25 \\
85 & 24 & 22 & 34 & 26 \\
90 & 26 & 24 & 36 & 28 \\
\hline
\end{tabular}

distance between stations and fewer speed restrictions. The increase in initial acceleration also made little difference, as it is for a relatively short duration while the train is accelerating; more time is spent in the constant power region of the tractive effort curve. An increase in the maximum power of the trains would make more difference to capacity, but the equipment cost and energy consumption would increase. The relative increase of 1.15 to $1.3 \mathrm{~m} /$ $\mathrm{s}^{2}$ in acceleration is also rather less than the relative increase of 0.5 to $0.75 \mathrm{~m} / \mathrm{s}^{2}$ in braking.

\subsubsection{Sensitivity to Dwell Time}

The results of the sensitivity study on dwell time for the existing manually driven trains and lineside signalling are given in Table 5. Reductions in dwell time below the nominal $30 \mathrm{~s}$ assumed for the modelling appear to provide a small increase in capacity, but increases in dwell time can result in large reductions in capacity.

For comparison, testing a $60 \mathrm{~s}$ dwell time in the moving block signalling/ATO case reduced the capacity from 30 to $22 \mathrm{tph}$. Poor design of the platform-train interface and poor management of passenger flows within the train and within the station therefore have the potential to negate the capacity benefits of investments in vehicles, signalling and power supply if dwell times become the critical factor.

\subsubsection{Energy Consumption}

The simulation results also provide journey times and energy consumption of the trains between South Gosforth and Pelaw (and vice versa), and Table 6 illustrates the relative differences in journey time and energy consumption between manual driving and ATO, for both the
Table 5 Sensitivity of capacity to dwell times

\begin{tabular}{ll}
\hline Dwell time (s) & Capacity (tph) \\
\hline 15 & 21 \\
30 (as above) & 20 \\
45 & 18 \\
60 & 16 \\
\hline
\end{tabular}

existing and the higher performance rolling stock. These results are for the existing lineside signalling.

As noted in Sect. 4.2, the simulation results assume allout running. The trade-off between journey times, energy consumption and overall capacity illustrated in Table 6 can be altered by changing the driving style, for example, by introducing coasting [34, 35]. Likewise, increasing the maximum power rating of the higher performance rolling stock above that of the existing Metrocars will also alter this trade-off. The choices in rolling stock and signalling design, the timetable and the operation of the network are ultimately a balance between many competing factors that aim to optimise the benefits of the system in relation to the costs.

\subsubsection{Accuracy/Reliability of Results}

The multi-train simulation software measures journey times and headways to a resolution of one second, and the results of the validation exercise carried out previously suggest an overall accuracy of around $3 \mathrm{~s}$ for station-tostation journey times. Comparison against the differences in headway for the driving/signalling options considered implies that this accuracy is sufficient for the main conclusions about the capacity benefits of driverless trains to be valid, and also suggests that the differences in capacity 
Table 6 Relative journey times and energy consumption

\begin{tabular}{lll}
\hline & Journey time & Energy consumption \\
\hline Existing rolling stock & & \\
Manual driving $\left(0.5 \mathrm{~m} / \mathrm{s}^{2}\right)$ & - & - \\
ATO $\left(0.75 \mathrm{~m} / \mathrm{s}^{2}\right)$ & $-7 \%$ & $+8 \%$ \\
Higher performance rolling stock & & \\
Manual driving $\left(0.5 \mathrm{~m} / \mathrm{s}^{2}\right)$ & $-2 \%$ & $+1 \%$ \\
ATO $\left(0.75 \mathrm{~m} / \mathrm{s}^{2}\right)$ & $-8 \%$ & $+12 \%$ \\
\hline
\end{tabular}

Higher performance rolling stock: $100 \mathrm{~km} / \mathrm{h}$ maximum speed, $1.3 \mathrm{~m} / \mathrm{s}^{2}$ initial acceleration from the higher performance rolling stock tested are not significant.

Further development of this work would be to move to more detailed investigations of specific timetables for the entire Metro network, including studies of the likely dwell time at each station, and Monte Carlo simulation of pseudorandom delays to estimate actual timetable stability [47]. This would provide a sound basis for the development of new commercial timetables to take advantage of the potential capacity increases offered by driverless trains.

\section{Conclusions}

The aim of this paper was to undertake a high-level examination of the potential benefits and obstacles of converting an existing metro system to driverless operation, defined for this paper as encompassing GoA 3 and 4 in the IEC 62267 standard. The Tyne and Wear Metro system was used as a case study to illustrate the operational changes possible, with particular focus on the capacity benefits of automation.

A simulation exercise demonstrated that automatic train operation (GoA 2 and above) of the Tyne and Wear Metro can provide significant increases in capacity when implemented in conjunction with resignalling. Low adhesion conditions are a significant risk to achieving this capacity increase reliably, and additional measures to mitigate low adhesion conditions would be required. Station dwell times also represent a potential risk to capacity, and the influence of passenger flows when boarding/alighting at stations on dwell time should also be considered. These risks may be partly mitigated by the signalling and control system chosen providing better resilience against delays.

The capital costs of this signalling and control equipment (and other systems required for driverless operation, such as remote monitoring and passenger communications) are likely to be significant, and will have associated maintenance costs. The relatively modest passenger base of the Metro suggests that large capital investments or increases in operational costs would be difficult to justify, as increasing passenger capacity is not an immediate requirement. GoA 4 operation could nonetheless take advantage of the increased capacity to offer higher frequency services at much lower marginal cost than GoA 2 or 3. This has been a key technology for allowing metro systems with a modest passenger base to be commercially viable, by offering a service frequency high enough to attract sufficient passengers without corresponding high operational costs. The actual staffing level will affect ridership, and the actual trade-off of staff level and costs will vary from city to city.

Comparison can be drawn with the other metro systems in the UK to consider the feasibility of introducing the technology to the Metro. London Underground carries far more passengers relative to its size than the Metro, with overcrowding being a higher priority problem as a result. ATO (GoA 2) is therefore being implemented across the network to increase capacity [53], but further automation is strongly resisted by the rail trade unions. The Docklands Light Railway was designed and operated as GoA 3 from its construction and opening in 1987 , but has fully segregated right-of-way that is mostly elevated [26]. The Glasgow Subway is currently being converted from GoA 2 to GoA 4, to reduce costs and increase service flexibility, but the entire route is within underground tunnels [40]. The Metro was predominantly converted from existing railway infrastructure built in the mid-nineteenth century, and also runs over Network Rail tracks shared with main line rail services. As such, the investment required to prevent incursions onto the infrastructure (a prerequisite to GoA 3 or 4) and retain compatibility with main line trains is likely to be very high by comparison with these other systems. At present, this appears to be the largest single obstacle to driverless operation on the Metro, and suggests that it is not currently a particularly promising application for driverless trains. Nonetheless, development work for autonomous vehicles in the automotive sector and increased automation in main line railways have the potential to help overcome this obstacle. Furthermore, the issues examined in this paper are equally applicable to other metro systems across the world, and can be directly transferred and applied to studies of other metro systems considering further automation. 
Acknowledgements This paper is based on input provided by two undergraduate students, Chun Nok Cheong and Ho Ki Yeung, who investigated the implementation of driverless operation on the Tyne and Wear Metro as part of their major projects at the School of Mechanical and Systems Engineering at Newcastle University. The simulations were conducted by the $\mathrm{PhD}$ student Jonathan Powell using an OpenTrack simulation model of the Tyne and Wear Metro network, built previously by Jonathan for his PhD project and subsequently also used for this paper. Special thanks to Dr Marin Marinov for publishing a number of rail simulation-related studies relevant to this work, and encouragement to work on this topic.

Open Access This article is distributed under the terms of the Creative Commons Attribution 4.0 International License (http://crea tivecommons.org/licenses/by/4.0/), which permits unrestricted use, distribution, and reproduction in any medium, provided you give appropriate credit to the original author(s) and the source, provide a link to the Creative Commons license, and indicate if changes were made.

\section{References}

1. Mew GM (1964) The Post Office railway. Proc Inst Mech Eng 179(3A):39-56

2. Dell R, Manser AW (1964) Automatic driving of passenger trains on London Transport. Proc Inst Mech Eng 179(3A):24-38

3. Duffy MC (2003) Electric railways 1880-1990. IET, London

4. Barwell FT, Coales JP, Barton HHC (1964) Application of automatic control theory to railways. Proc Inst Mech Eng 179(3A):8-23

5. Nelson DO (2013) Automated metro operations: challenges and opportunities. Paper presented at the 3rd international conference on urban public transportation systems, Paris, 17-20 Nov 2013

6. Ruhlmann H (1964) Automatic driving of trains. Proc Inst Mech Eng 179(3A):106-112

7. METPO Info International (2015) Moscow Subway History, 1935-2015. METPO Info International (2015 digest):8-15

8. Kekonius O, Kallberg NO (1964) The automatic pilot for underground trains in Stockholm. Proc Inst Mech Eng 179(3A):71-79

9. La Vanguardia Española (1966) Presente y Futuro del Metropolitano de Barcelona. La Vanguardia Española 18 Aug:19

10. Ito T, Ebihara H (1964) Automatic train operation by programme control. Proc Inst Mech Eng 179(3A):57-61

11. UITP (2016) World Report on Metro Automation. UITP, Brussels

12. Malla R (2013) The trend to automation. Paper presented at the 4th Automated Metro Seminar, London, 6 Sept 2013

13. European Rail Research Advisory Council (2012) Metro, light rail and tram systems in Europe

14. Howard DF (1976) Tyne and Wear Metro-a modern rapid transit system. Proc Inst Mech Eng 190:121-136

15. Howard DF, Layfield P (1981) Tyne and Wear Metro: concept, organization and operation. Proc Inst Civ Eng 70(4):651-668

16. Davoudi S, Gillard A, Healey P, Pullen B, Raybould S, Robinson F, Silcock D, Usher D, Wymer C (1993) The longer term effects of the Tyne and Wear Metro. Transport Research Laboratory, Crowthorne

17. Mackay KR (1999) Sunderland metro-challenge and opportunity. Proc ICE-Munic Eng 133(2):53-63

18. Nexus (2014) Metro strategy 2030 background information

19. Milroy IP (1980) Aspects of automatic train control. Dissertation, Loughborough University

20. Gunselmann W (2005) Technologies for increased energy efficiency in railway systems. Paper presented at the 2005 European conference on power electronics and applications, Dresden, 11-14 Sept 2005

21. Thomas $P$ (2006) The feasibility case for converting existing heavy metro systems to driverless operation. In: Allan J, Brebbia CA, Rumsey AF, Scuitto G, Sone S, Goodman CJ (eds) Computers in railways X. WIT Press, Ashurst, pp 363-372

22. Georgescu MP (2006) Driverless CBTC—specific requirements for CBTC systems to overcome operation challenges. In: Allan J, Brebbia CA, Rumsey AF, Scuitto G, Sone S, Goodman CJ (eds) Computers in railways X. WIT Press, Ashurst, pp 401-409

23. Vuchic VR (2014) Maintaining performance with full automation. Metro Report International (March):36-39

24. Cohen JM, Barron AS, Anderson RJ, Graham DJ (2015) Impacts of unattended train operations on productivity and efficiency in metropolitan railways. Transp Res Rec 2534:75-83

25. Hernandez M, Malla R (2016) Metro automation: a safe and flexible solution. Pub Transp Int (1/2016):24-25

26. Lockyear MJ (1996) Changing track: moving-block railway signalling. IEE Rev 42(1):21-25

27. Fabbian $F$ (2006) Converting existing service to fully automatic operation. In: Allan J, Brebbia CA, Rumsey AF, Scuitto G, Sone $\mathrm{S}$, Goodman CJ (eds) Computers in railways X. WIT Press, Ashurst, pp 373-379

28. Ossent T (2010) Paris experience in driverless metro: increasing capacity, reducing costs. Paper presented at the World Metrorail Congress, London, 22-25 March 2010

29. Chiusolo S, Dicembre A, Ricci S, Sorace F (2011) Automation of high density metro lines: Rome line A case study. Paper presented at automated people movers and transit systems 2011, Paris, 22-25 May 2011

30. Karvonen H, Aaltonen I, Wahlström M, Salo L, Savioja P, Norros L (2011) Hidden roles of the train driver: a challenge for metro automation. Interact Comput 23(4):289-298

31. Fraszczyk A, Brown P, Duan S (2015) Public perception of driverless trains. Urban Rail Transit 1(2):78-86

32. Gill DC (1998) The impact of moving block train control on heavy metros. Paper presented at the international conference on developments in mass transit systems, London, 20-23 April 1998

33. Thomas PD (1980) Longitudinal control for guided transport. Dissertation, Loughborough University

34. Malavasi G, Palleschi P, Ricci S (2011) Driving and operation strategies for traction-energy saving in mass rapid transit systems. Proc Inst Mech Eng Part F 225(5):475-482

35. Domínguez M, Fernández A, Cucala AP, Lukaszewicz P (2011) Optimal design of metro automatic train operation speed profiles for reducing energy consumption. Proc Inst Mech Eng Part F 225(5):463-474

36. Powell JP, Palacín R (2015) Passenger stability within moving railway vehicles: limits on maximum longitudinal acceleration. Urban Rail Transit 1(2):95-103

37. McKenna D (1964) Operating requirements of an automatic railway. Proc Inst Mech Eng 179(3A):3-7

38. Mancone P (2011) Automation of Line 1: a real opportunity for the Parisian Metro. Paper presented at automated people movers and transit systems 2011, Paris, 22-25 May 2011

39. BBC (2014) Driverless Tube trains: unions vow 'war' over plan. BBC News, 28 Feb 2014. http://www.bbc.co.uk/news/uk-eng land-london-26381175. Accessed 21 Sept 2016

40. Shirres D (2016) Subway revival. Rail Engineer 143 (Sept):16-21

41. Morton D, Litterst R (2013) Optimizing headway with ETCS and ATO. Paper presented at the 10th world congress on railway research, Sydney, 25-27 Nov 2013

42. Bienfait B, Zoetardt P, Barnard B (2012) Automatic train operation: the mandatory improvement for ETCS applications. Paper presented at aspect 2012, London, 10-12 Sept 2012 
43. Powell JP, Palacín R (2015) Benchmarking suburban, regional and freight train driving styles in a mixed-traffic railway. Paper presented at the RailNewcastle international conference, Newcastle upon Tyne, 15-17 July 2015

44. Rowe G (2009) Leaves, Adhesion and ATO. Paper presented at modern train braking-further development in stopping, Derby, 19 Nov 2009

45. Wales J, Marinov M (2015) Analysis of delays and delay mitigation on a metropolitan rail network using event based simulation. Simul Model Pract Theory 52:52-77

46. Motraghi A, Marinov MV (2012) Analysis of urban freight by rail using event based simulation. Simul Model Pract Theory 25:73-89

47. Landex A (2008) Methods to estimate railway capacity and passenger delays. Dissertation, Technical University of Denmark
48. UIC (2004) Capacity. UIC, Paris

49. Dicembre A, Ricci S (2011) Railway traffic on high density urban corridors: capacity, signalling and timetable. J Rail Transp Plan Manag 1(2):59-68

50. Martínez I, Vitriano B, Fernández A, Cucala AP (2007) Statistical dwell time model for metro lines. In: Brebbia CA (ed) Urban transport XIII. Urban transport and the environment in the 21st century. Wessex Institute of Technology, Ashurst, pp 223-232

51. Vollenwyder K (2002) Linear motor propulsion for urban transit. Paper presented at the 17th international conference on magnetically levitated systems and linear drives, Lausanne

52. Adhesion Working Group (2004) Managing low adhesion

53. Kessel C (2015) LU Northern line goes CBTC. Rail Engineer 127 (May):74-77 